\title{
The harmonisation between architecture and nature in the desert of Iran with a hot and dry climate
}

\author{
F. Daneshpanah ${ }^{1} \&$ M. Mousavizade ${ }^{2}$ \\ ${ }^{1}$ Department of Architecture, SAMA College, \\ Khorasgan Islamic Azad University, Iran \\ ${ }^{2}$ Department of Architecture, \\ Khorasgan Islamic Azad University, Iran
}

\begin{abstract}
In the modern world, achieving the methods of design and construction with the aim of achieving a balance between art and architecture in a special environment is very important. Iran, a four season country with different climates, could be used as a case study about the harmonization between architecture and nature. By reviewing the architecture and urban design in a hot and dry environment, we discover that the traditional architects have had several solutions to overcome the climate challenges. The conclusion of these solutions leads to the creation of practical and executive works. These architectural methods are the main subjects of study in this paper. Some of these methods are as follows: solar orientation of the functional spaces in the buildings; functioning of the complex system of the air circulation between the wind-catcher, fountain, and interior spaces; designing special spaces for different seasons around the inner courtyard in private houses; creating special spaces for different seasons (for example, colonnade, garden, underground gardens, cellar); smart light control systems in openings. In conclusion we can use modern eco-architecture and apply such design solutions to achieve the passive systems for architecture in hot and dry climates without incurring much expense.
\end{abstract}

Keywords: traditional architecture, desert houses, wind-catcher, passive air conditioning systems, sash windows, court yard, natural lighting. 


\section{Introduction}

A hot and dry climate exists in most areas of Iran's plateau, which is located in the Asia continent.

This area, with its desert nature and different visages of urbanization and architecture, has been favoured for eco-architectural researches. In Iran, on the central plateau, there are areas which have a dry and hot climate, and because of intense and direct radiation of the sun during the day, the weather is very hot and dry most of the time.

Because the sun radiation produces 700 to 800 kilo calorie of energy per hour in each square meter of horizontal surfaces, and because of scattered plant cover, reflection of this radiation causes warm weather. Lack of humidity in these areas causes a meaningful variation in the range of the temperature between the day and night which is around $25^{\circ} \mathrm{C}$, since the temperature in the hot days of summer reaches to $40^{\circ} \mathrm{C}-50^{\circ} \mathrm{C}$ and, it reduces to 15 to $20^{\circ}$ at nights Kasmai [1].

\section{Desert cities, desert houses}

In such a climate, the organic plans of the desert cities have been formed based on the solar orientation in a compacted and complex texture.

The passages in these cities are seen with smart orientation against the sunshine and there are also narrow passages with high walls. The passages are covered with roofs in some places which makes shady spaces for pedestrians.

Now we want to review the architectural practical solutions in these houses. As mentioned in the abstract, the first general technique is the orientation of the buildings.

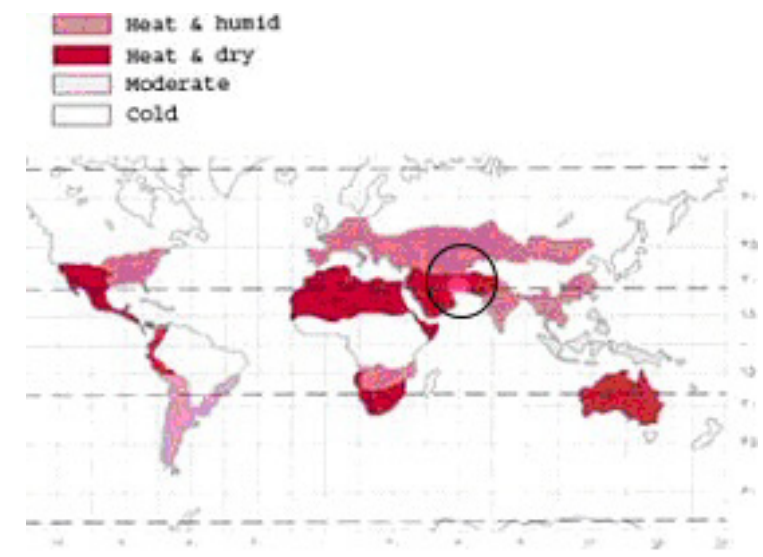

Figure 1: The position of Iran in Asia. 

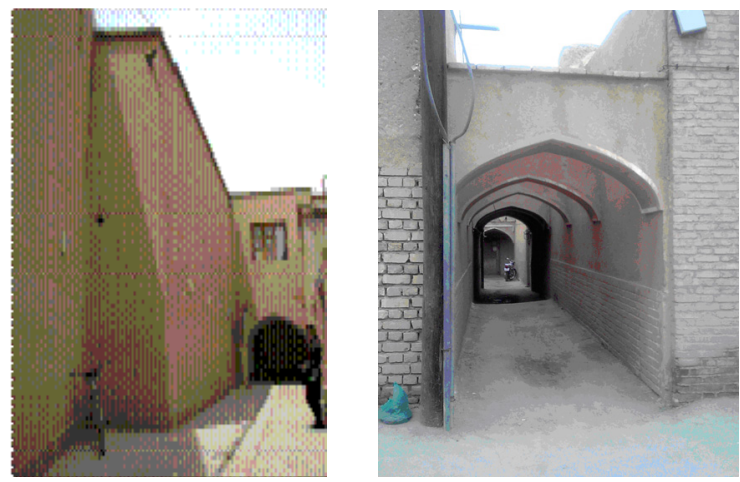

Figure 2: $\quad$ Two views of a passage.

\subsection{The building's solar orientation}

In these areas the orientation of houses is often toward the east-west axis, so the wider surfaces with long time function stand in the best position to get the desired lighting and temperature from the north and south Ghobadina [2]. The results of such an orientation are:

1. In the hot seasons, the main spaces receive a little light and heat and in the cold seasons, they receive more light and heat.

2. None of the main spaces receive the light and from the west in the sunset.

\subsection{The work of the complex system of the air circulation between the wind-catcher, fountain, and interior space}

This solution, as a creative way in making natural comfortable conditions, has been built by different methods and forms. The main element of this system is a wind-catcher. Development and evolutional trend of the form and function or optimization of defects of the wind-catcher structures have always been aimed at better exploitation. So the structures of the wind-catcher, except the aesthetic parameters, have been influenced by the following factors:

1. The direction of the desirable wind blow in different periods and seasons of the year.

2. The speed of the wind blow.

3. The height of the desirable wind blow.

The structure of a wind-catcher, as shown in Figure 3, consists of a perpendicular channel. This channel is a rectangular cubic usually made of mud brick for insulation and is often covered by clay and straw. The inner layer of the channel is covered by a plaster layer.

In some channels, the main channel is divided into several perpendicular sub channels Mahmoudi [3]. According to traditional architects this division has been done for two reasons: 

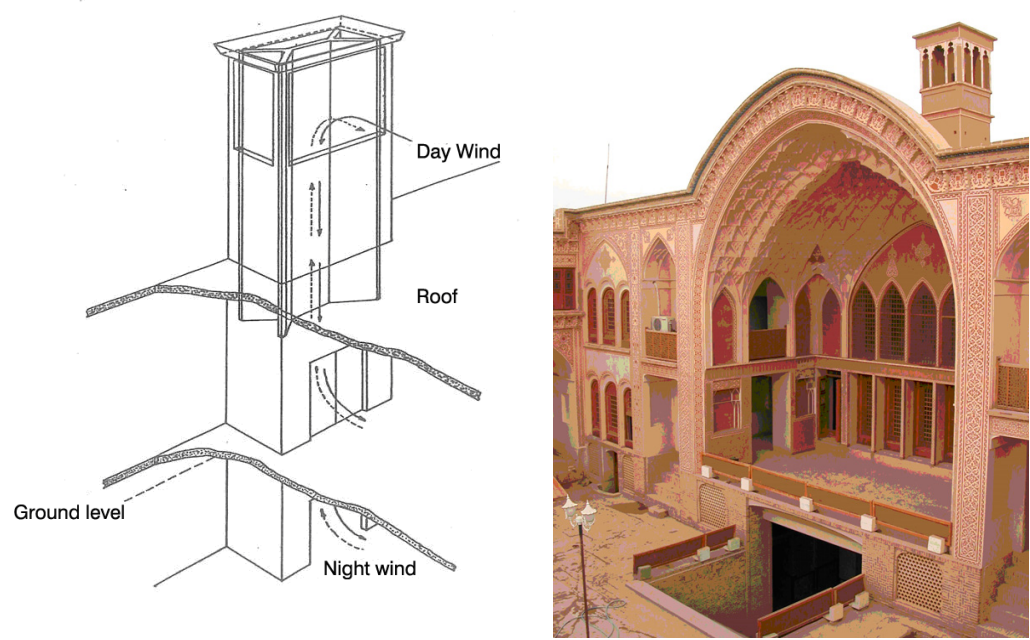

Figure 3: The usual construction of a wind-catcher.
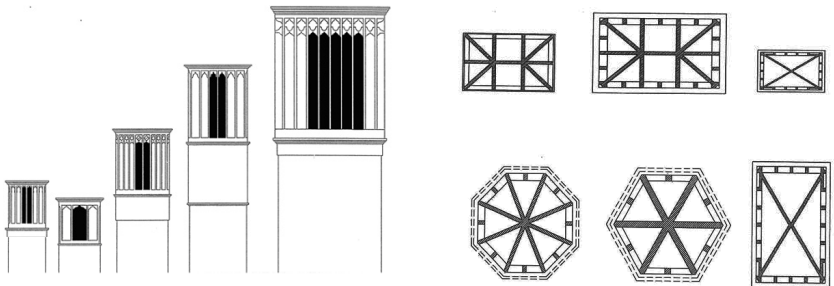

Figure 4: Various shapes of wind-catcher.

1. In some cases the pores of the wind-catcher are oriented in more than one side to get desirable winds in different periods of the year or day. In such a design one channel acts as a receiver of the wind and the others act as the transmitter of the inner air to the outside. The circulation happens because of creating positive pressure in the pore toward the wind direction and negative pressure in other pores which is not toward the wind.

2. Creating smaller channels to speed up the wind as a fluid substance. These sub channels may be seen with different cross sections, for example, it can be seen in the fig 4.

The height of a wind-catcher is normally between $3-8 \mathrm{~m}$. In some particular cases, you can see wind-catcher with the height around $1.5 \mathrm{~m}$ and above or rarely a height around $9 \mathrm{~m}$. Two major factors determine the height of wind-catcher:

1. Increasing the height raises the speed of the wind.

2 In the desert area raising the height of wind-catcher increases more temperature gap between the upper and the lower points of the wind-catcher Mahmoudi [4]. 


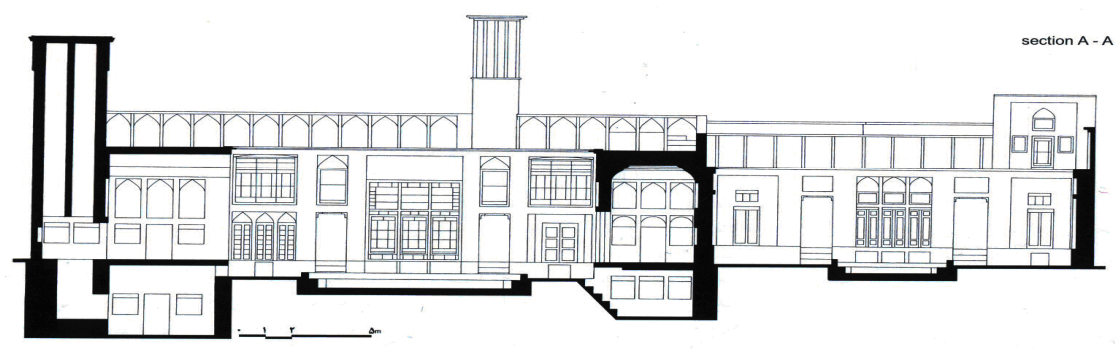

Figure 5: $\quad$ Relation between wind-catcher and spaces (Haji-Ghasemi [5]).
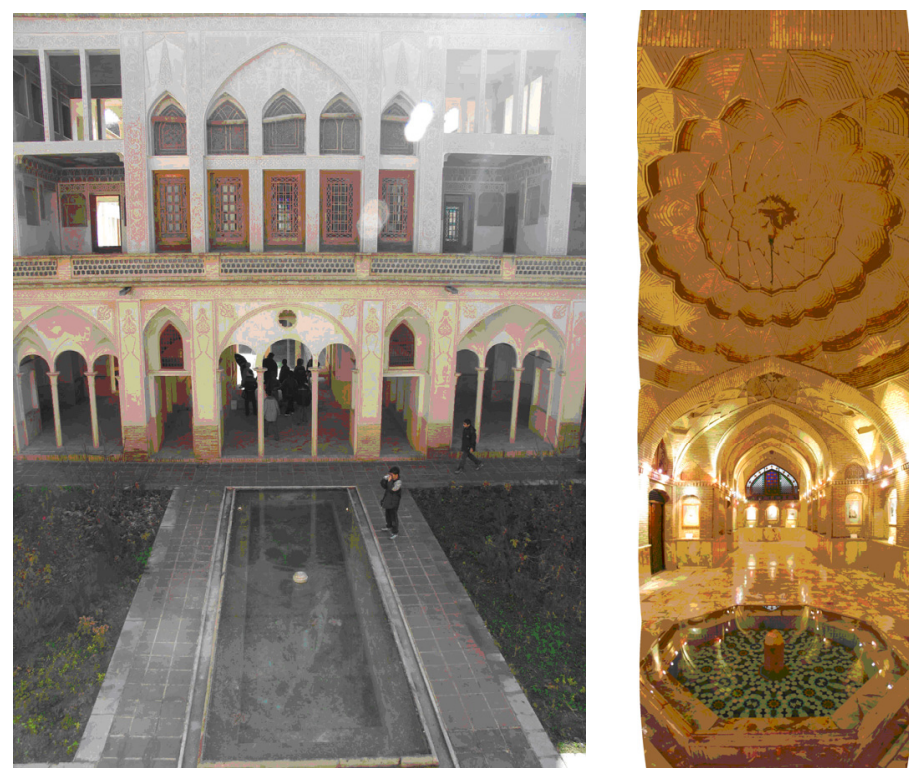

Figure 6: Fountain in the basement "Hozkhaneh".

In the same way it was addressed in the evolution path of the structure of the wind-catcher, the function of the element has also been designed based on three ecological factors:

1. The wind speed.

2. The wind direction.

3. The temperature difference between the air mass at the bottom and top of the wind-catcher.

It's worth mentioning that, the third factor acts when the speed of the wind is lower than $2.5 \mathrm{~m} / \mathrm{s}$. If the wind flows in a speed higher than $2.5 \mathrm{~m} / \mathrm{s}$, it overcomes the pressure difference [6]. The second factor is the main factor in the typology of the wind-catcher, determining that the wind-catcher is two, four, six or eightsided. Another trend in designing passive system of the wind-catcher, to create 
desirable air in the inner spaces of a building, is to pull in the cold and humid air flow which passes through the water inside the fountain.

In the most cases in residential houses, a wind-catcher is used to cool the air of the main hall which is a summer-sitting space. It's worth noting that, in a desert house, the spaces based on the ratio of the sunshine they receive are known as the summer-sitting and the winter-sitting spaces. Another summersitting space that is included in this passive air conditioning system is the basement.

\subsection{Designing special spaces in private houses for different seasons of the year, including the inner courtyard, underground gardens and colonnades}

The inner courtyard is located at the centre of a house which creates different sides. In these sides the heat of the sun's rays are different. Such a design creates functional spaces for different seasons. This special lighting was used for a sitting room, so it is called summer sitting spaces or winter sitting spaces.

Below, a residential plan is presented as a sample of different functional spaces. The winter-sitting spaces are shown in blue (down side of the figure) and the summer-sitting spaces are shown in red (up side of the figure) Badkhan [6].

The height of the walls can also affect the lighting and the temperature. The yard's walls are high, which create shadows in the yard and the rooms at most hours of the day.

The other surprising trend in some of the desert houses, which is employed to create shady spaces, is a garden in the underground level inside the main yard.

1. The underground garden is in the shadow at most of the day time, because it is located at the 4-6m below ground.

2. Since it's surrounded by underground cool space, it is colder than the main yard.

3. As the underground garden is located below ground the insulation is naturally completed.

Colonnade (Iwan) is a shady space located between the main hall and the yard. Colonnade is covered by a roof and walls on three sides, which prevents the main hall from exposure to sunshine and heat.

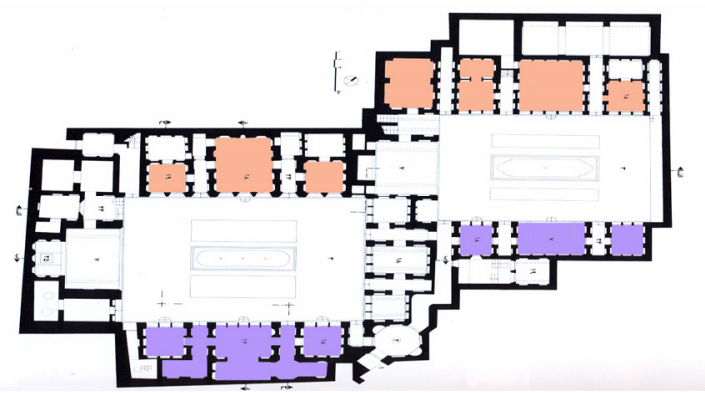

Figure 7: A house with two inner courtyards (Haji-Ghasemi [7]). 


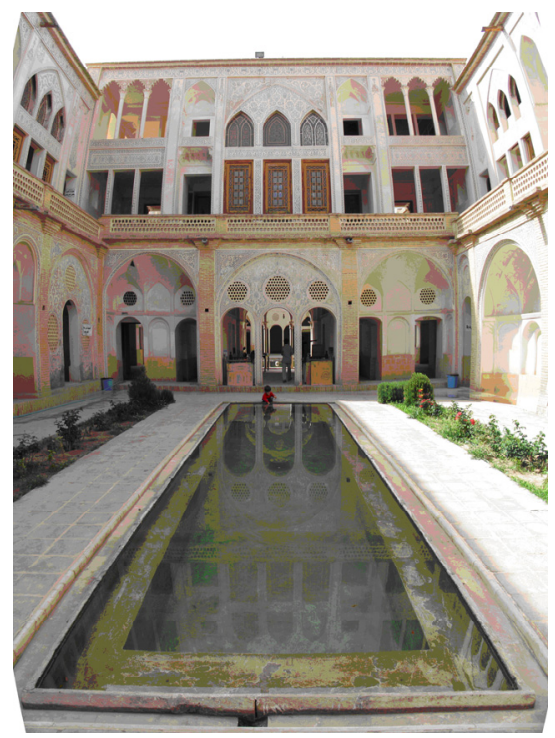

Figure 8: A view of an underground garden.

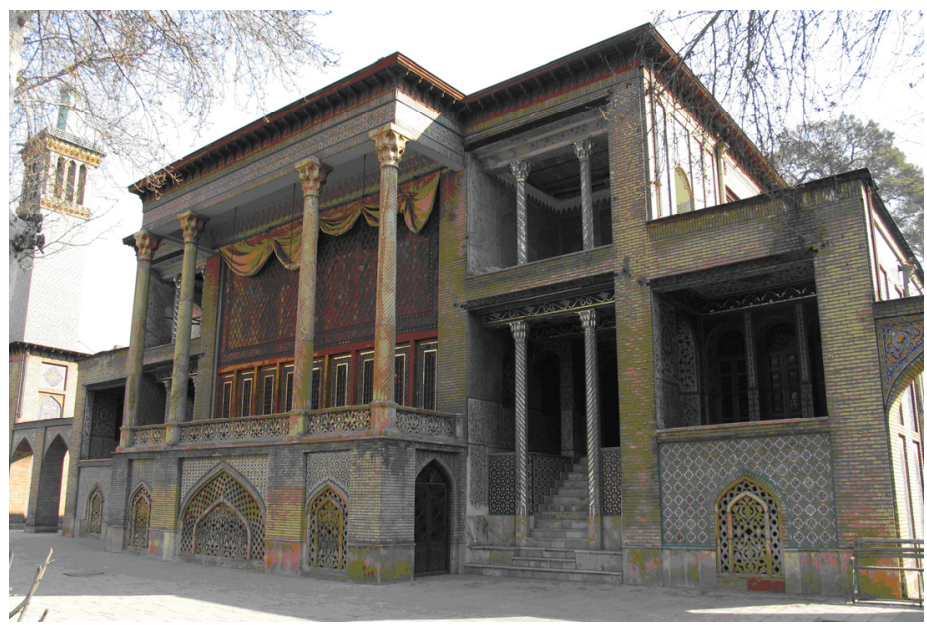

Figure 9: Different depths of colonnade (Iwan).

\subsection{Creative use and control of the light}

In addition to attention to the control of the light in designing plans, Iranian architects have paid attention to design and construction of details and decoration of the buildings as well as the wise control of the light.

The example of this technique for facing the light are: 
1. Pores covered with lattice screens in the ceiling control the entrance of heat and sunshine.

2. The transparent surfaces created with the suitable design, quality, partition and texture. Transparent surfaces control the light as a filter. The screen structure also prevents the transparent body from heat by creating shadows in

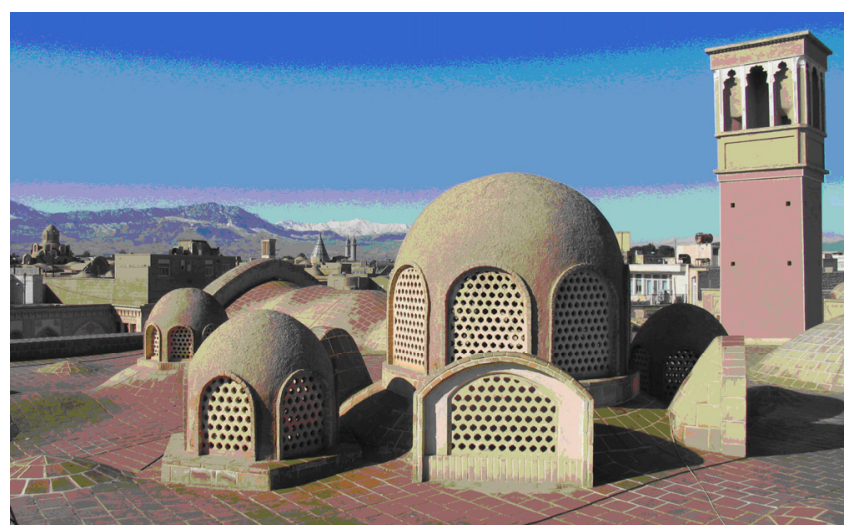

Figure 10: View of complex pores from the roof.

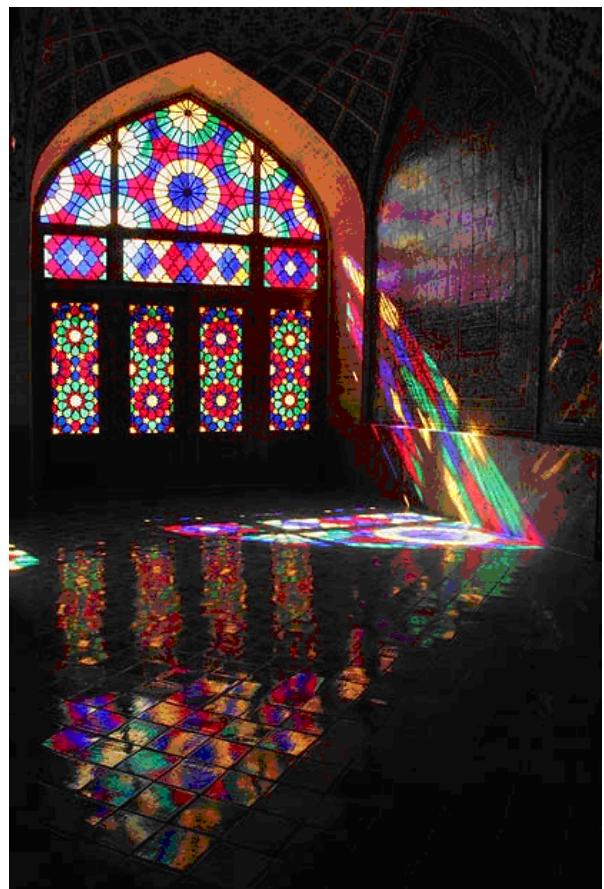

Figure 11: Partition, texture and coloured glasses control the light as a filter. 


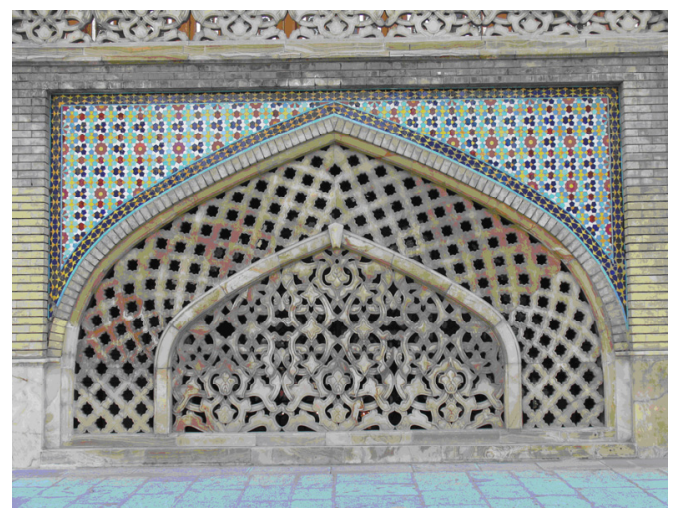

Figure 12: A transparent surface as a window.

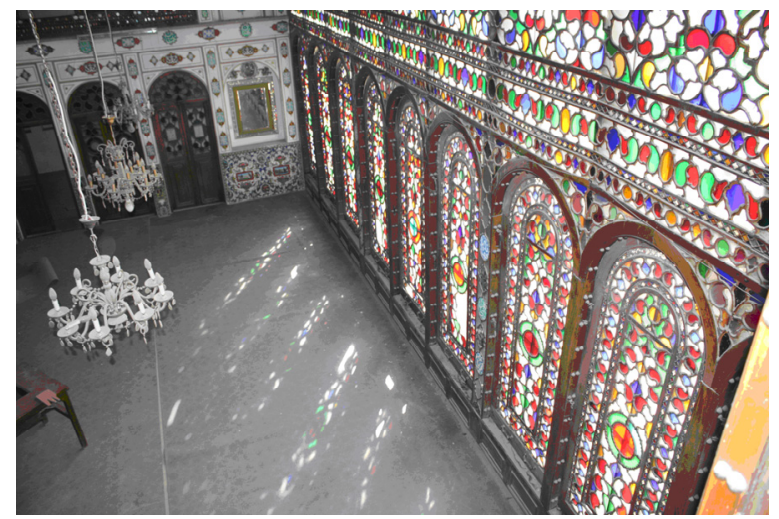

Figure 13: The coloured glasses in a window.
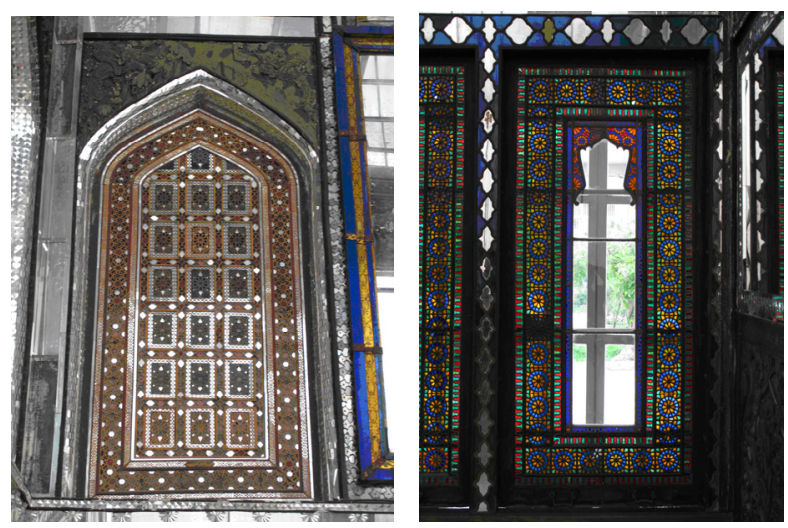

Figure 14: The mirrors in a window.

WIT Transactions on Ecology and the Environment, Vol 128, (c) 2010 WIT Press www.witpress.com, ISSN 1743-3541 (on-line) 
the same transparent layer. The result is that the warm air circulation will not happen by the windows.

3. Using coloured glasses in the windows controls the ratio of sunshine entering into the building.

\subsection{Creative design and the way of using the materials}

The first effective factor for choosing materials in desert areas is to be able to act as an insulator against the sun's heat. Henceforth, the majority of the materials from the structure to the cover of the surfaces consists of wood and mud brick.

The walls of 60 to $80 \mathrm{~cm}$, or even $1 \mathrm{~m}$ thick, are made of mud brick and act as high insulators for the interior.

Usage of the materials which attract heat such as stone are limited and they are used in the foundation to prevent the building from the effects of the humidity.

The soil gained from digging the ground was used as the material of building the houses. The humidity of this soil caused to cool the weather of the inner space.

\section{Conclusion}

Obviously in the modern world paying attention to the design principles based on the climatic condition does not mean omitting the active system, but it means optimizing energy costs.

Design principles in hot and dry climates lead to implement practical techniques in designing details and elements in the modern architecture such as below:

1. Designing condensed buildings: building should be condensed and inner directed so that the minimum surfaces are exposed to the sun radiation.

2. Attention to the north - south direction: It should be noticed that surfaces which need more lighting and less heat should take the light from the north and south directions. The other point is that the western surfaces are critical surfaces as they receive the direct sunshine and maximum heat but the lighting they receive is not desirable.
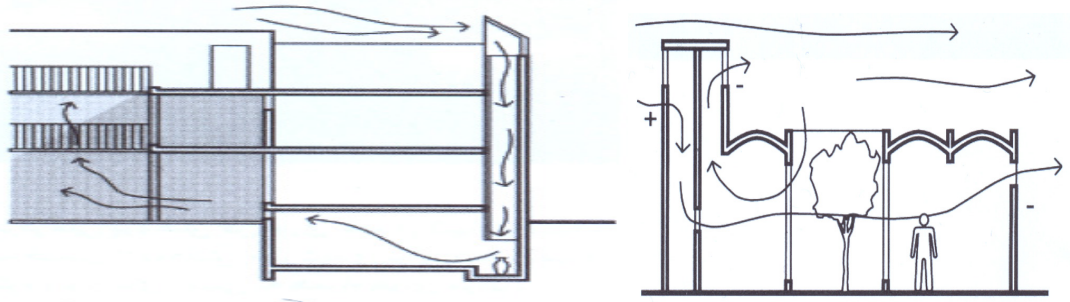

Figure 15: Wind-catcher and courtyard in modern architecture (Holger Koch [8]). 
3. Attention to the direction of cool and clear wind in designing wind-catchers: The orientation of the wind-catchers depends on the wind as an important factor. A wind-catcher's direction should be in a way that receives most of the cool and clear winds.

4. Creating natural shady and cool spaces: this can happen by taking benefits of shadow of trees and using fountains as a natural cooling system.

5. Attention and more creativity in designing windows: Taking benefit of this procedure can decrease the waste of energy and help in receiving the most desirable lighting. This solution can be achieved by taking benefit of the following elements:

5-1. Transparent surfaces: management of the amount of the light entered to the spaces is possible by using transparent surfaces such as lattice screens.

5-2. Coloured glasses: management of the wave length and creating the desired light which enters into the spaces is possible by using coloured glasses. Using this type of glasses attract and reflect the desired sun rays better than the ordinary glasses.

5-3. Mirrors: taking advantage of mirrors in windows can reflect the sun light and reduce the heat in inner spaces.

5-4. Sash and double shelled windows: this element can help in insulation by its unique design. The body of sash window is made of a wooden frame which carries woodcuts in the form various plants and geometric shapes. Sash windows are usually in a rectangular form and their upper part has

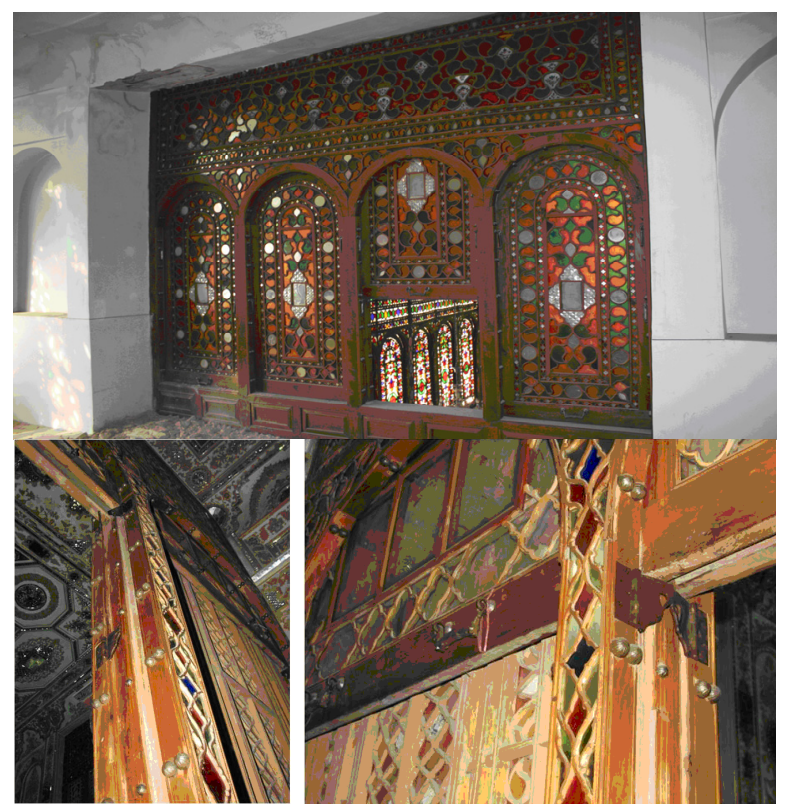

Figure 16: A sash window and its details. 
colour glasses which are in arch or rectangular shapes. Such windows and doors are widely employed in the houses of hot and dry climatic areas to adjust and soften the light. Using wooden double-shelled in this kind of window causes an air layer between two layers of window (double shelled) which acts as a heat insulation system and prevents waste of the energy.

5-5 Knot-works: using various knot-works in the frame of windows causes breaks of the light radiation and prevents the radiation of the direct sun light into the inner space. According to the calculations in opposite knot-works, $40 \%$ of the surface is composed of glass and the rest is composed of wood as the main material of the window.
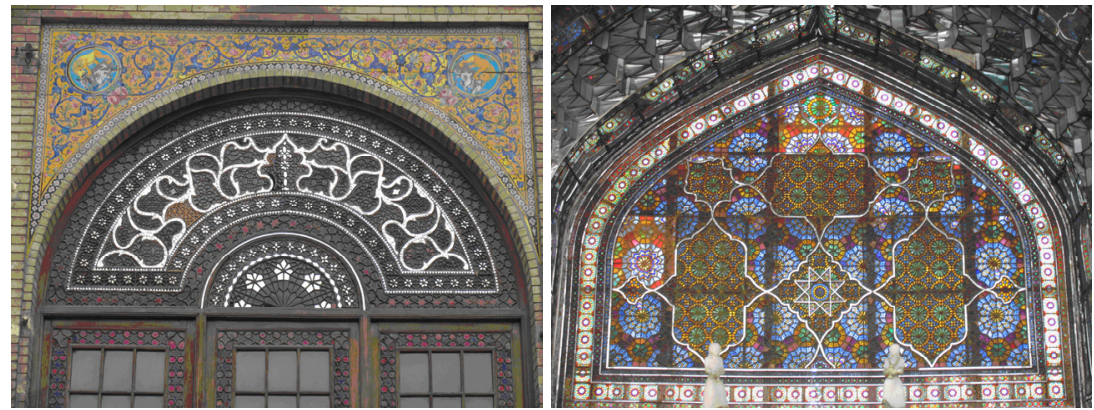

Figure 17: Breaking the light radiation by various knot-works.

\section{References}

[1] Kasmai, M, Climate, Khak: Esafahn, p.82, 2003.

[2] Ghobadian, V, Climate Analysis of the Traditional Iranian Buildings, Tehran University: Tehran, pp: 6-7, 2006.

[3] Mahmoudi, M, Badgir (The element of Iran architecture), Yazda: Tehran, pp.76-79, 2009.

[4] Mahmoudi, M, Badgir (The element of Iran architecture), Yazda: Tehran, pp.80-115, 2009.

[5] Haji-Ghasemi, K, Ganjnameh cyclopaedia of Iranian Islamic architecture, Yazd houses, cultural and Heritage organization: Tehran, volume14, p.90, 2005.

[6] Battle McCarthy Consulting Engineers, Natural and wind driven ventilation, (Cahpter2), Wind Towers, Academy Press, 1999.

[7] Haji-Ghasemi, K, Ganjnameh cyclopaedia of Iranian Islamic architecture, Yazd houses, cultural and Heritage organization: Tehran, volume14, p.75, 2005.

[8] Holger Koch., N, The built environment (Chapter 2), Stay Cool: A Design Guide for the Built Environment in Hot Climate, Earthscan Publications: United Kingdom, 2002. 